\title{
Development of Earth Device for Freight Car's Plain Bearing
}

Hideshi KAKISHIMA

Senior Researcher,

Frictional Materials

Tetsuya HOSOYA

Former Senior Researcher,

Lubricating Materials Laboratory, Materials Technology Division

\section{Yasuo SATO}

Senior Researcher,

Vehicle \& Bogie Parts Strength, Vehicle Structure Technology Division

\section{Yasunari TERADA}

Deputy Manager,

Design \& Manufacture, Research and Development Promotion Division

Sinichi HASE

Director,

Power Supply Technology Division

Plain bearings equipped with railway freight cars frequently suffered from surface damage caused by electrical current. This paper describes a newly developed earth device as designed to prevent electrical conduction in such bearings. The developed earth device can be installed on existing freight car axle boxes and readily assembled and removed upon regular inspection. In a durability test for electrical conduction until $21,600 \mathrm{~km}$ equivalent journey distance, the electrical resistance of the earth device was $100-300 \mathrm{~m} \Omega$. It also satisfied the requirements of a durability test for mechanical vibration in accordance with JIS E 4031.

Keywords: freight car, plain bearing, earth device for prevention of electrical pitting

\section{Introduction}

Bearings - the components that support rotating axles and shafts - are one of the most important machinery elements. The two main types are rolling bearings and sliding bearings. In various types of railway vehicle, rolling bearings are used to support the axles, the shaft of the main motor, the running gears and other parts. In some freight cars, sliding bearings are used for the axle bearings; these are referred to as plain bearings.

Electrical pitting $[1,2,3]$ is a type of surface damage that occurs in rolling bearings and plain bearings. The damage caused by bearing current is due to discharge between rolling elements and the race surface in rolling bearings, and between the sliding surface and journal in plain bearings. Electrical pitting brings pit or wear to these surfaces and deteriorates lubricants. Because electrical pitting is an undesirable phenomenon during service, its prevention is a matter of vital importance in railway vehicles.

To prevent the electrical pitting, earth devices for axle rolling bearings $[4,5]$ are widely used in railway vehicles including freight cars with axial rolling bearings. Since plain bearings differ in structure from rolling bearings, earth devices for axle rolling bearings are inapplicable to plain bearings. Accordingly, this paper describes a newly developed earth device designed to prevent electrical conduction into freight-car plain bearings.

\section{Outline of the earth device and development procedure}

The two types of earth system are axial end earth and radial earth. To prevent electrical pitting, either type can shunt the current that flows through the bearings. With the axle rolling bearing, its outer race is held by the axle box, and its inner race is locked onto the axle; the maximum axial-direction displacement of the outer race to adhere to the axle (the inner race) is equal to the axial gap of the bearing. The axial gap of the JT11B axle rolling bearings used in freight cars is approximately $0.5 \mathrm{~mm}$ to $0.7 \mathrm{~mm}$, while that of plain bearings is approximately $10 \mathrm{~mm}$. Since the axial gap of the plain bearing differs considerably from that of the rolling bearing, the axial end earth devices used for axle rolling bearings are inapplicable to plain bearings. Furthermore, if the radial earth system is applied to a freight car, comprehensive changes must be made to its trucks. In this development, we therefore designed and manufactured a new axial end earth device to prevent electrical conduction into freight-car plain bearings. 
In the development of the earth device, we considered the following points:

(1) It should be possible to install the device in existing axle boxes.

(2) It should be possible to readily assemble and remove the device upon regular inspection.

(3) The device should not seriously affect service in the event of failure.

Figure 1 shows the location of the mounted earth device, and Fig. 2 outlines its basic structure. It is mounted on a collar edge face, and consists of a rotating part, a holding part, a conducting substance, a ball bearing and a lead wire. The conducting substance (electrically conductive grease or carbon particles) is put into the conducting substance enclosure section, between the rotating part and the holding part. The rotating part rotates together with the journal, and the holding part maintains the tension of the lead wire. When the lead wire is connected mechanically to the inside wall of the axle box, the axle box and the journal are connected electrically. This electrical connection shunts the current that flows through the bearings.

The electrical resistance between the plain bearing and the journal varies widely according to the situation; when the journal is not rotating, the electrical resistance with metallic contact is very small; during rotation, the

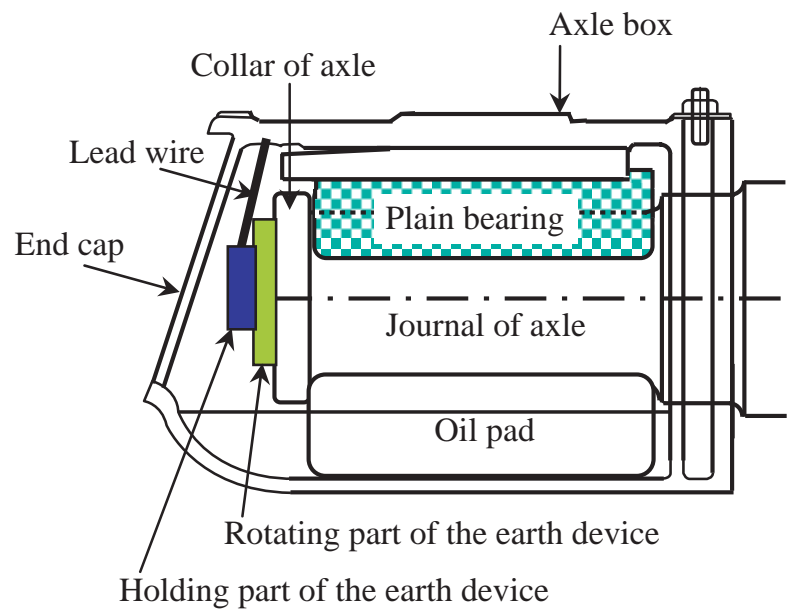

Fig. 1 Mounting location of the earth device

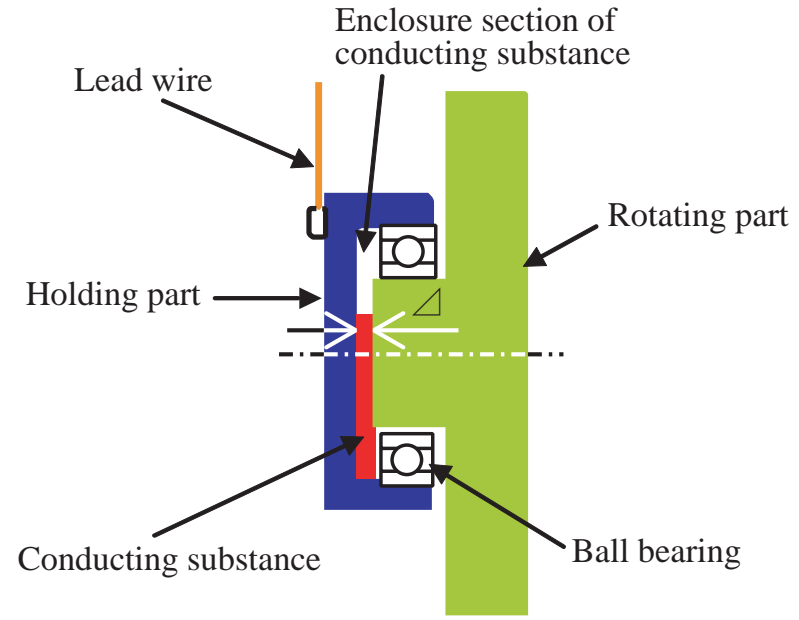

Fig. 2 Basic structure of the earth device

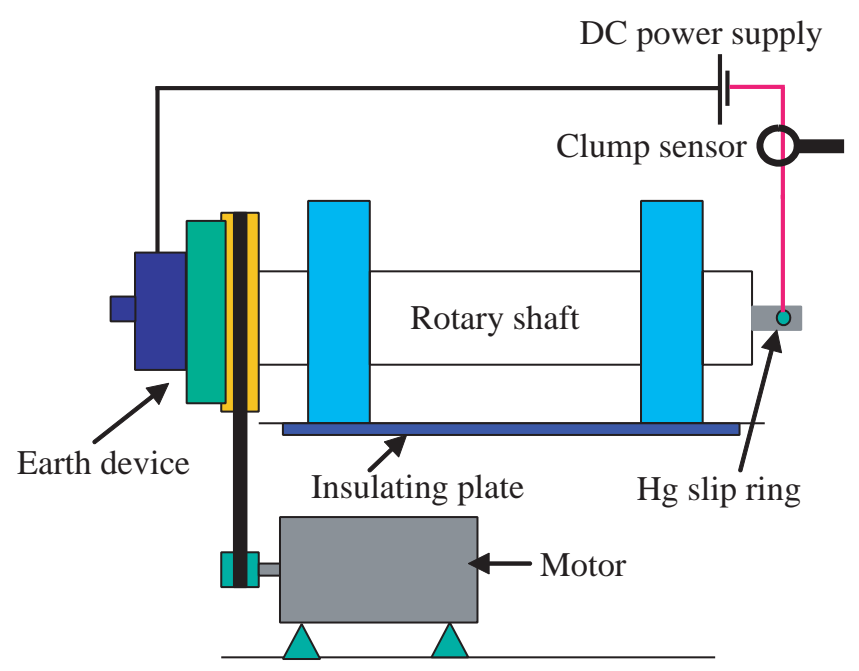

Fig. 3 Illustration of the electrical conduction test
apparatus

value is higher due to the generation of a lubricating oil film. One of the targets of this development is the limitation of electrical resistance between the rotating part and the holding part to level under $500 \mathrm{~m} \Omega$.

We made several prototypes of the earth device, which varied in terms of the electrical substance type, the amount of electrical substance, the dimensions of the enclosure section and the ball bearing type. In addition, we carried out testing to evaluate the electrical conduction properties of these prototypes. Figure 3 is an illustration of the electrical conduction tests. The prototype is set on the axial end of the rotary shaft, an $\mathrm{Hg}$ slip ring is set on the opposite side, and a DC power supply connects the prototype and the $\mathrm{Hg}$ slip ring. In this way, an electrical circuit including the prototype is constructed.

The electrical conduction properties of these prototypes were evaluated in terms of electrical resistance, which was calculated from the supply voltage and the current running through the circuit. The tests revealed the following points in regard to improving the earth device:

(1) As the conductive substance in the enclosure section, the carbon particles have high performance as compared with the electrically conductive greases.

(2) The electrical conduction properties improve when the thickness of the space $\Delta$ as shown in Fig. 2 is smaller.

(3) If carbon particles are packed fully into the enclosure section, the electrical conduction properties improve, but the temperature of the earth device rises rapidly.

(4) Since the carbon particles do not intrude into the ball bearing, it is necessary to use bearings with a contact seal.

(5) To prevent electrical pitting in the ball bearing and improve the electrical conductive properties, the bearing has to be lubricated with electrically conductive grease.

We developed the earth device of the final product by 


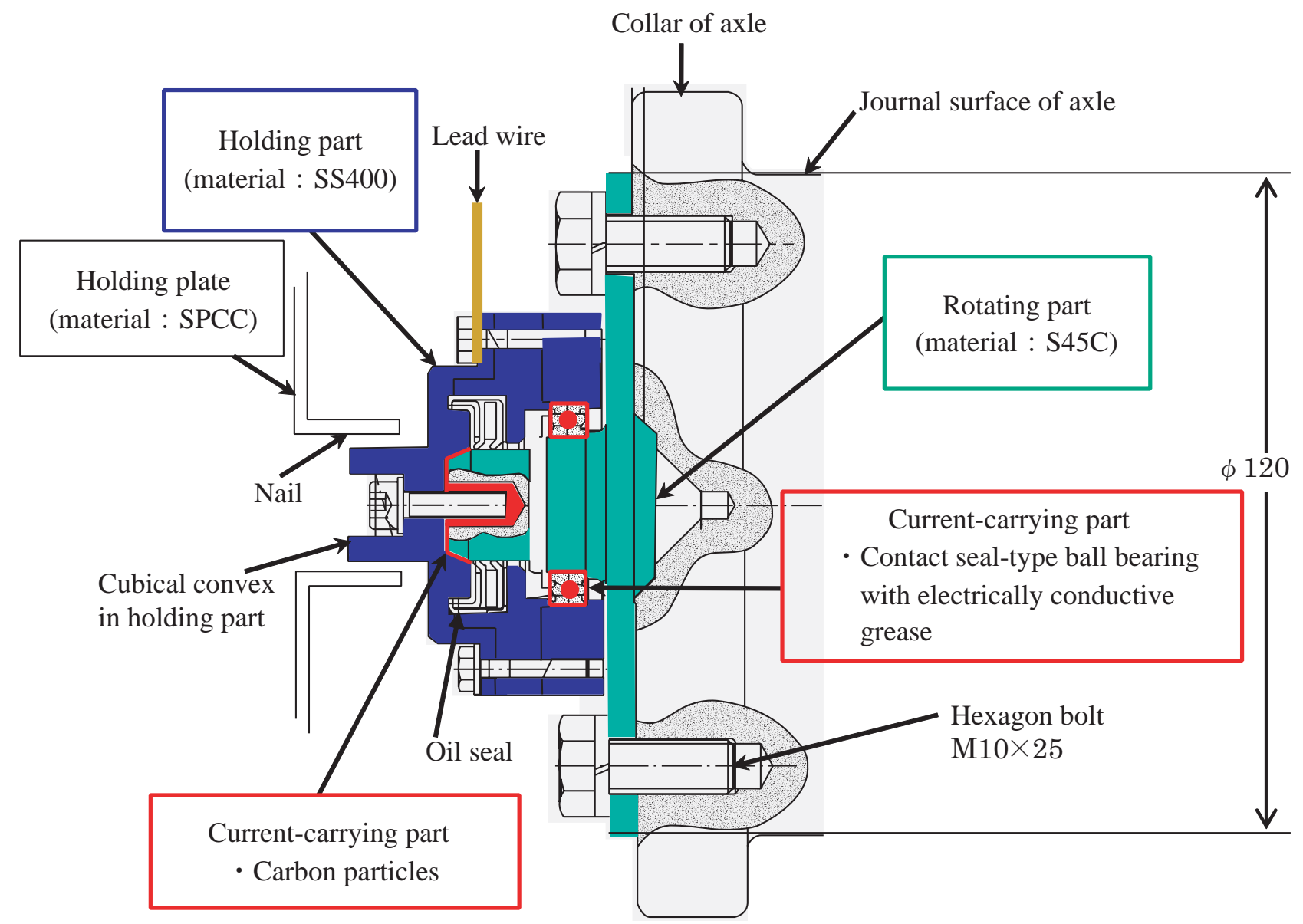

Fig. 4 Structure of the earth device

incorporating the above points. We carried out an assembly test for an existing axle box, a durability test for mechanical vibration and a durability test for electrical conduction with the earth device developed.

\section{The structure of the earth device}

Figure 4 shows the structure of the developed earth device. The rotating part is fixed by eight hexagon bolts on the collar edge face of the journal. The holding part is connected to the rotating part through a ball bearing and an oil seal. The earth device has two current-carrying parts; one is the ball bearing with electrically conductive grease lubricant, and the other is the enclosure section of the conducting substance that contains carbon particles, as shown in Fig. 5. The enclosure section consists of a dent in the rotating part and a clearance of $0.5 \mathrm{~mm}$ between the rotating part and the holding part. The clearance has a tapered section and a vertical section, and 0.35 $\mathrm{g}$ of carbon particles are inserted into the dent and the clearance. A carbon coating [6] with a thickness of 1 to 2 $\mu \mathrm{m}$ covers both tapered section surfaces to prevent oxidation of the enclosure section surfaces.

The holding part has a cubical convex to prevent rotation when the rotating part (i.e., the axle) rotates. It is

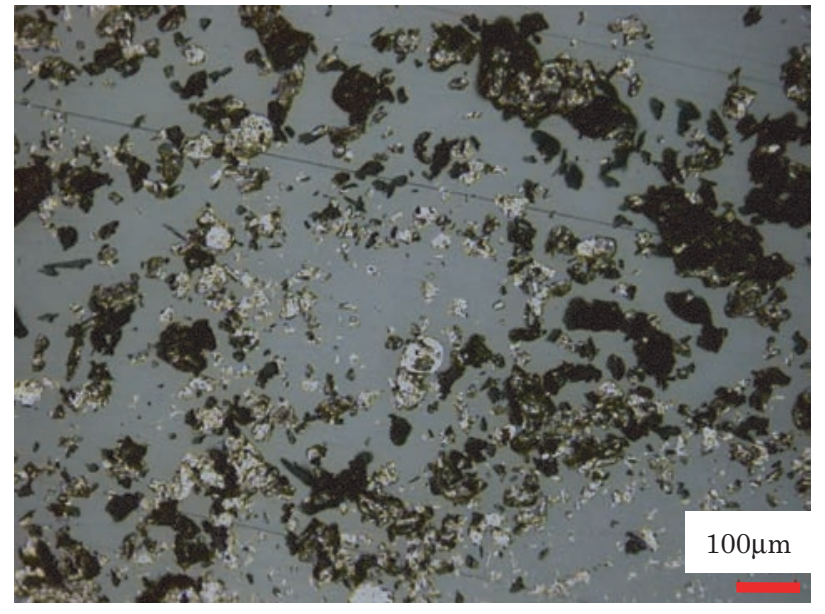

Fig. 5 Appearance of the carbon particles used

held by two nails, which are part of a holding plate newly created in this development. If the rotational resistance between the holding part and the rotating part increases in the event of ball bearing failure, the nails bend. The condition of the earth device is indicated by the condition of the nails on the holding plate. 


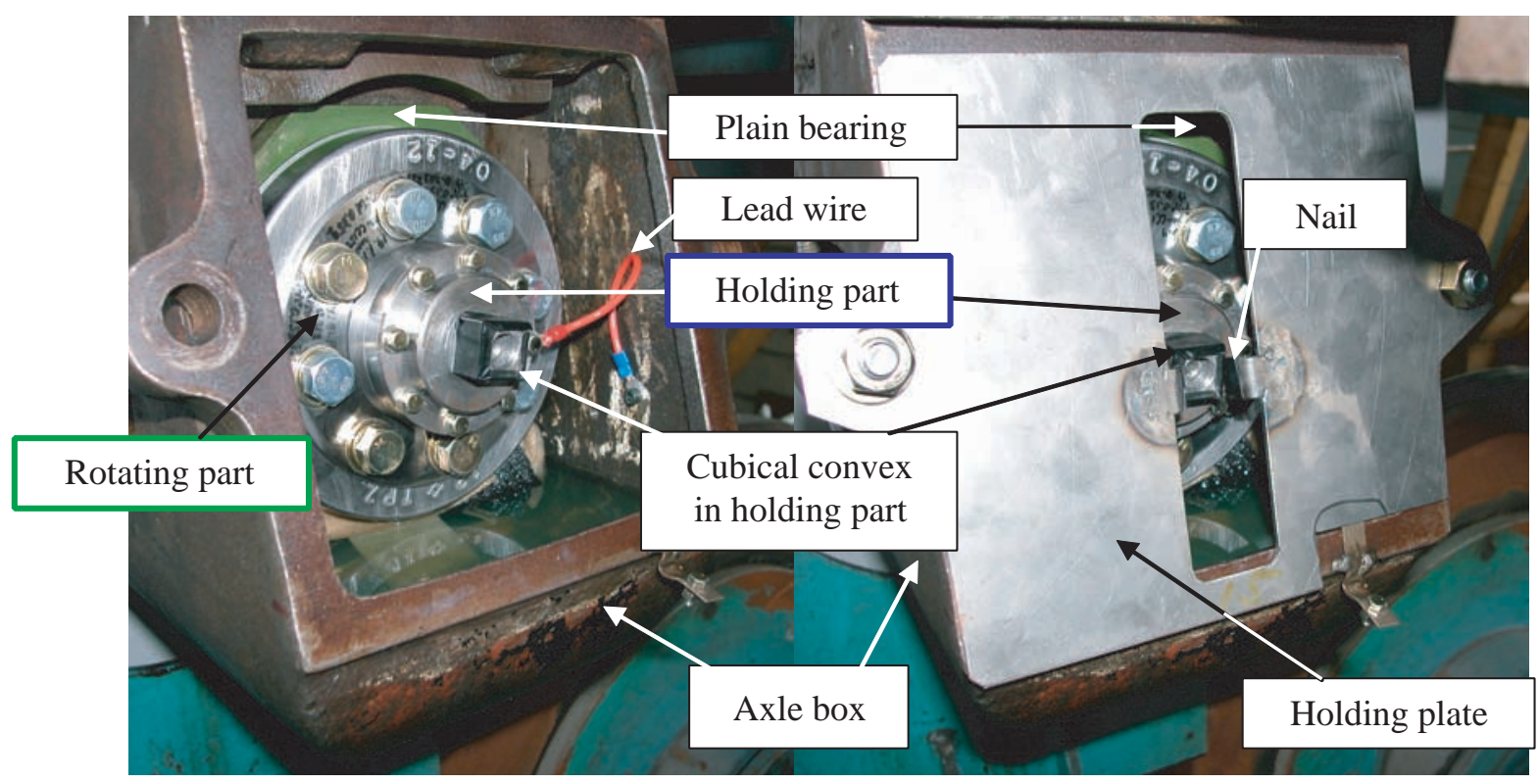

(1) With end cap and

(2) With holding plate fittied holding plate removed

Fig. 6 The earth device assembled in an axle box

\section{Assembly test for the actual axle box}

The journal undergoes the axial displacement (with a maximum value of $10 \mathrm{~mm}$ ) relative to the plain bearing. It is therefore essential to verify that the earth device does not touch the end cap in the axle box when the maximum axial displacement is applied. We carried out an assembly test for the existing axle box using axle bearing inspection apparatus which consisted of existing plain bearings, the existing axle box and wheel set. The apparatus can produce the maximum axial displacement $(10 \mathrm{~mm})$ for the existing axle box (with the plain bearing). Figure 6 shows the earth device installation into the existing axle box. The test results show that the earth device does not touch the end cap in the axle box when the maximum axial displacement is applied.

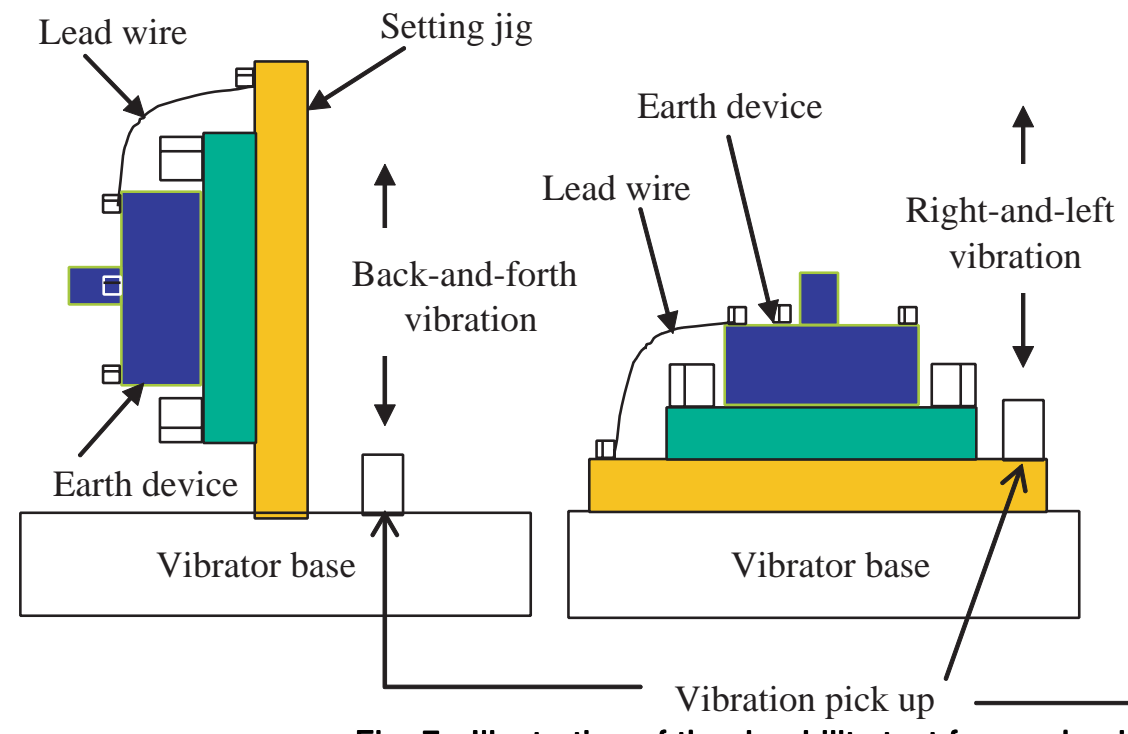

Fig. 7 Illustration of the durability test for mechanical vibration

\section{The durability test for mechanical vibration}

We carried out a mechanical vibration durability test for the earth device in accordance with JIS E 4031 [7]. Table 1 shows the test conditions, and Fig. 7 shows a schematic illustration of the test. Since the earth device is a

\section{Table 1 Conditions of the durability test for mechanical vibration}

\begin{tabular}{|c|c|c|}
\hline Frequency & \multicolumn{2}{|c|}{$50 \mathrm{~Hz}$} \\
\hline Amplitude & \multicolumn{2}{|c|}{$3.5 \mathrm{~mm}$} \\
\hline Acceleration amplitude & \multicolumn{2}{|c|}{$340 \mathrm{~m} / \mathrm{s}^{2}$} \\
\hline \multirow{3}{*}{ Duration } & Back-and-forth & 2 hours \\
\cline { 2 - 3 } & Right-and-left & 2 hours \\
\cline { 2 - 3 } & Vertical & 4 hours \\
\hline
\end{tabular}

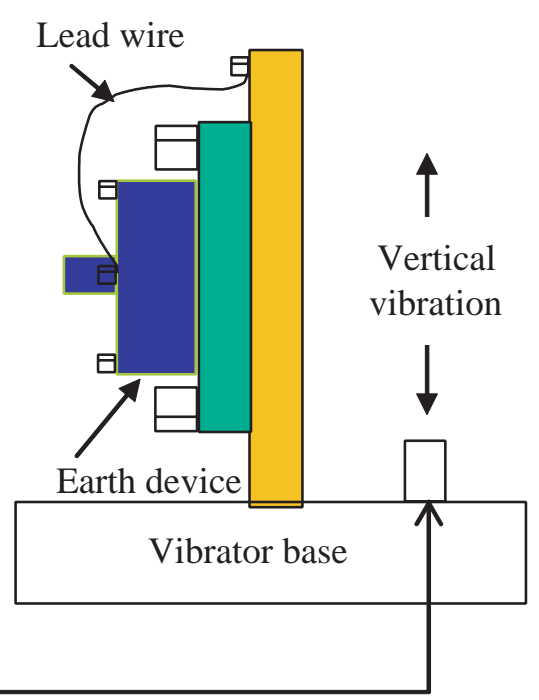


rolling stock part that is installed in the un-sprung part of the truck, the test was carried out in accordance with the test methods for vibration of un-sprung truck parts (JIS E 40316 class). In each test, we monitored the frequencies and accelerations with a vibration pick-up mounted on a vibrator base.

During the tests, neither lead wire rupture nor bolt detachment occurred. Moreover, after the tests, no carbon particle leaks, bolt loss or ball bearing rupture were seen. The earth device therefore satisfied the requirements under durability testing for mechanical vibration in accordance with JIS E 4031.

\section{The durability test for electrical conduction}

\subsection{Test conditions}

The durability test for electrical conduction is to verify the electrical resistance of the earth device at less than $500 \mathrm{~m} \Omega$, which is a target of this development for regular inspections. The test was carried out with the same apparatus used in the electrical conduction test for the prototypes (Fig. 3). Before carrying out the test, we considered the relevant variables in terms of duration time, electrical conduction conditions etc. The regular inspections for plain bearing axle box are carried out on a 90 day cycle. It is therefore necessary for the earth device to maintain an electrical resistance of less than $500 \mathrm{~m} \Omega$ beyond 90 days. The maximum journey distance of freight cars with plain bearings is about $200 \mathrm{~km}$ a day under normal operation. This means that it was necessary to carry out the test for an equivalent journey distance of more than $18,000 \mathrm{~km}(90$ days $\times 200 \mathrm{~km} /$ day $)$. The equivalent journey distance used in the test was $21,600 \mathrm{~km}$, representing an increase of 20 percent over the $18,000 \mathrm{~km}$ value. The rotation speed of the rotating part was $500 \mathrm{RPM}$, because that of the axle is $500 \mathrm{RPM}$ when a freight car with plain bearings runs at $75 \mathrm{~km} / \mathrm{h}$, which is the maximum speed. The total duration times was therefore 288 hours $(21,600 \mathrm{~km} / 75 \mathrm{~km} / \mathrm{h})$.

Since no data is available on the current that runs through the plain bearing axle box, the electrical conduction conditions of the test were decided based on knowledge of the current that runs through the rolling bearing axle box. In 1981, the predecessor of the Railway Technical Research Institute, carried out test runs of freight cars with rolling bearings toward the prevention of electrical pitting. Information regarding the current that runs through the rolling bearing axle box was obtained as follows:

(1) Currents fluctuate wildly and currents are frequently beyond 10 amperes instantaneously.

(2) Currents flow suddenly through the axle box with durations of several seconds to ten seconds.

(3) The direction of currents is mainly from vehicles to rails.

(4) Currents running through axle boxes occur much more frequently during power running of electrical locomotives.

Research on preventing the electrical pitting of roller bearings in railway vehicles was also reported in the So- viet Union in 1975 as per [8]. It was reported that current flow occurs for up to 25 percent of the journey time for freight cars and up to 10 percent for passenger cars.

We decided the electrical conduction conditions in the test based on the knowledge outlined above. The total time for electrical conduction was therefore 72 hours, which was a quarter of the duration time. We applied a voltage of $2 \mathrm{~V}$ between the rotating part and the holding part 24 times on a 3 -hourly basis ( 24 times $\times 3$ hours $=72$ hours $)$. The voltage can be supplied the current with 20 A to the developed earth device when the rotating part is stationary. The direction of the current flow was from the holding part to the rotating part, assuming the electrical conduction from vehicles to rails. During the electrical conduction test, we measured the variations in the current and calculated the electrical resistance of the earth device. Table 2 shows the test conditions as a whole.

\section{Table 2 Conditions of the durability test for electrical conduction}

\begin{tabular}{|l|l|}
\hline Rotating speed & $500 \mathrm{rpm}$ \\
\hline Total of equivalent journey distance & $21,600 \mathrm{~km}$ \\
\hline Duration & 288 hours \\
\hline Total time of electrical conduction & $\begin{array}{l}72 \text { hours, 1/4 of the duration } \\
(24 \text { times on a 3- hour) }\end{array}$ \\
\hline Applied voltage & 2 V (DC) \\
\hline Polarization & Holding part :,+ Rotating part:- \\
\hline
\end{tabular}

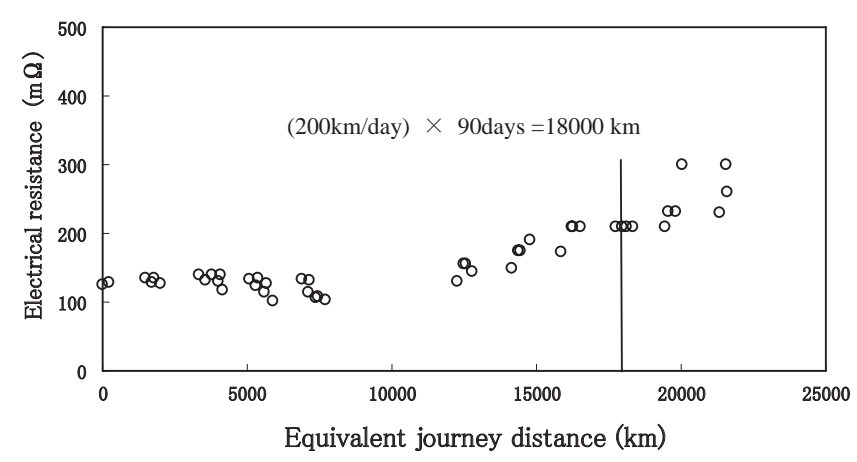

Fig. 8 The variation of electrical resistance in the earth device

\subsection{Test results}

Figure 8 shows the variation of electrical resistance in the earth device during the test. The open dots in the figure indicate the values calculated from variations in the current and supply voltage. Until an equivalent journey distance of $12,500 \mathrm{~km}$ from the start of the test, the electrical resistance moved in a transitional band of 100 to $150 \mathrm{~m} \Omega$ without increasing further, and no insulating occurred. After that, the electrical resistance increased little by little with higher equivalent journey distance values, but did not increase rapidly, and no insulating state occurred. In addition, the maximum value of the 
electrical resistance was $300 \mathrm{~m} \Omega$. After the durability test for electrical conduction, leaking of the carbon particles, losing of the bolts and breaking of the ball bearing did not occur. The durability test for electrical conduction to an equivalent journey distance of $21,600 \mathrm{~km}$ thus revealed the electrical resistance of the earth device to be 100 to $300 \mathrm{~m} \Omega$.

\section{Conclusions}

In this development, a new earth device for freight cars with plain bearings was developed. The device can be installed on existing freight car axle boxes, and readily assembled and removed upon regular inspection. In a durability test for electrical conduction until 21,600-km equivalent journey distance, the electrical resistance of the earth device was $100-300 \mathrm{~m} \Omega$. The earth device also satisfied the requirements of a durability test for mechanical vibration in accordance with JIS E 4031.

\section{Acknowledgment}

The authors would like to express their sincere gratitude to Japan Freight Railway Company for their cooperation in this study.

\section{References}

[1] Watanabe, T., "Rolling stock bearing and electric corrosion," Rolling Stock and Technology, No. 12, pp. 3-10 in 1995 (in Japanese).

[2] Boyd, J. and Kaufman, H.N., " The Causes and the Control of Electrical Currents in Bearings," Lubrication Engineering, January, pp. 28 - 35, 1959.

[3] Kakishima, H., et al., "Experimental Reproduction of Surface Damage of Plain Bearing under Electrical Conduction," RTRI Report, Vol. 18, No. 10, pp. 15 - 20, 2004 (in Japanese).

[4] Mulertt, C. and Meatay, P, (trans. Kitanaka) "Axle Bearing Protection from Electric Current Flow and Earth Current Unit Technology," Denkisha no Kagaku, Vol. 45, No. 8, pp. 45 - 48, 1992 (in Japanese).

[5] Nihon Ferraz Corp., "Earth Return Current in Rolling Stock," Denkisha no Kagaku, Vol. 47, No. 5, pp. 42 - 48, 1994 (in Japanese).

[6] Matsui, M. et al., "Improvement of Wear Performance of Wheel Specimens by Duplex Shot-peeing in Dry Rolling/Sliding Contact Test," RTRI Report, Vol. 21, No. 2, pp. 39 - 44, 2007 (in Japanese).

[7] Japanese Industrial Standard JIS E 4031(1994).

[8] О р л о в, М.В, “С ПО С ОБЫ У МЕ НШЕНИ Я ЛОВРЕЖДЕНИЯ ТЯГОВЫМ ТОКО М БУ КСОВЫХ РОЛИКОБЫХ ЛОДШИЛ НИКОВ ВАГОНОВ, В АГОНОВ, В е с тник, Ве с т ник В с е с о н о-и с след. ин т а ж.р т a, No.6, 1975. 